\title{
Effects of selective double portazygous disconnection and devascularization on hemodynamics of the portal venous system
}

\author{
Guang-quan Zong, Yang Fei, Jian Chen, Ren-min Liu, Yu-feng Xu
}

Department of General Surgery, the 81st Hospital of PLA, PLA Liver Center, Nanjing, China

\begin{abstract}
Aim: Selective double portazygous disconnection with preserving vagus (SDPDPV) is currently used for the therapy of portal hypertension. Doppler ultrasonography (DU) has been proposed for non-invasive evaluation of splanchnic hemodynamics, but the effect of SDPDPV on portal vein (PV) hemodynamics has not been analyzed with DU. This was the aim of the study. Material and methods: Two hundred and thirty six patients with cirrhotic portal hypertension who underwent either SDPDPV or pericardial devascularization with splenectomy (PDS) for variceal bleeding were enrolled. The hemodynamics parameter, operation-relevant information, change of lavatory examination data, postoperative complications, and clinical outcomes were analyzed. Results: The free portal pressure (FPP) in the SDPDPV group was significantly lower than the PDS group after operation $(\mathrm{p}<0.05)$. Velocities and blood flow of PV after SDPDPV decreased; however, when the hepatic artery (HA) and superior mesenteric vein (SMV) increased, the differences were significant $(\mathrm{p}<0.05)$. The correlation between the decreased FPP and changed blood flow of portal vein(PVF), hepatic artery (HAF) or superior mesenteric vein (SMVF) was significant $(\mathrm{p}<0.05)$ after SDPDPV. The difference between pre and postoperative values of portal congestion index $(\mathrm{CI})$ in SDPDPV was significant $(\mathrm{p}<0.05)$. Occurrences or development of postoperative rebleeding showed a great difference between the two groups $(\mathrm{p}<0.05)$. PVF and SMVF were significant independent indicators of postoperative rebleeding $(\mathrm{p}<$ 0.05). Conclusions: Compared with the PDS, the SDPDPV apparently decreased the blood velocity and blood flow of PV, and increased that of HA and SMV which has a beneficial effect on hepatic function and encourages the controlof the recurrent bleeding from varices. PVF and SMVF may be value indicators in predicting postoperative rebleeding.
\end{abstract}

Keywords: portal hypertension, devascularization, hemodynamics, Doppler ultrasonography

\section{Introduction}

Modest success has been achieved in the treatment of portal hypertension (PHT) with variceal hemorrhage in which surgery has a significant role to play. Far from becoming obsolete, surgery in its various forms continues to have a place in the management of it $[1,2]$. However, innovations in surgical approaches to variceal hemorrhage due to PHT require preoperative and postoperative knowledge of splanchnic venous anatomy. Doppler ultra-

Received 12.06.2014 Accepted 21.07.2014

Med Ultrason

2014, Vol. 16, No 4, 291-297

Corresponding author: Yang Fei MD

Department of General Surgery, the 81st

Hospital of PLA, PLA. Liver Center

Nanjing 210002, China.

Phone: +86-25-86648090

Fax: +86-25-80864499

E-mail: fei_yanggood@163.com sonography (DU) has been extensively used to evaluate patients with portal hypertension $[3,4]$. With this method an accurate, noninvasive visualization of splanchnic venous anatomy can be performed, together with the measurements of a number of parameters of the venous system. Using DU, a pathophysiological assessment of the splanchnic circulation is possible and moreover, splanchnic hemodynamic surgical effects can be verified. Recently, selective double portazygous disconnection with preserving vagus (SDPDPV), firstly reported by Zong et al [5] was used for the prevention from varice hemorrhage in patients with cirrhotic portal hypertension. DU could help in the study of splanchnic hemodynamics in depth.

We designed a retrospective cross-sectional study that included consecutive patients that had underwent either SDPDPV for variceal bleeding in order to evaluate the effect of SDPDPV on splanchnic hemodynamic parameters using DU. 


\section{Materials and methods}

\section{General Information}

The study population comprised 236 variceal bleeders with cirrhosis PHT managed by surgery in the period between February 2007 and January 2013 at our hospital: 138 patients received SDPDPV and 98 PDS. The diagnoses of these patients were all confirmed by endoscopy or DU. Our indications for operations include episodes of gastroesophageal variceal hemorrhage with a 1-month interval between the last attack and date of surgical procedure, hemorrhage that could not be controlled by medical and endoscopic therapy, or thrombocytopenia (platelets count under $80 \times 10^{3} / \mathrm{mm}^{3}$ ) with gastroesophageal varices due to hypersplenism related to cirrhosis. According to current consensus of therapy in portal hypertension revised on the Baveno $\mathrm{V}$ et al [6], and salvage procedure recommended by García-Pagán et al [7], patients with high risk varices (grade 2 and 3, or grade 1 with red spots) were excluded. The patients had no concomitant serious cardiopulmonary diseases or chronic duodenal ulcers. The characteristics of the two surgical groups were summarized in table I. They were examined within 1-3 days preoperatively. Endoscopy or a barium meal examination was performed within 14 days before the operation to define the grade of varices. Patients were randomly arranged to undergo either SDPDPV or PDS procedure. Clinical variables including episodes of recurrent hemorrhage, encephalopathy, and thrombosis were examined postoperatively. In our studies, rebleeding was defined as at least $400 \mathrm{ml}$ blood transfusion requirement and/or a decrease in the hematocrit to less than $30 \%$.

\section{Operative technique}

SDPDPV procedure was performed through an expanded left subcostal incision. The FPP is measured by inserting a catheter into the portal trunk through a branch of the right gastroepiploic vein. After conventional extreme splenectomy, the FPP is measured again. The proximal stomach was devascularized close to the gastric wall just above the crow's foot along the lesser curvature from the incisura angularis up to the esophagus. Dissecting anterior Serosa layer and the left lateral peritoneum covering the esophagus, and separating the muscle layer carefully, paraesophageal vein was exposed. Following by lifting the stomach and dissecting gastropancreatic fold around the gastroesophageal junction, the left gastric artery and left gastric vein were exposed. The gastric branch of the left gastric vein and branches of left gastric artery were disconnected and suture ligated close to the gastric wall of lesser curvature in order to preserve the trunk of left gastric vein and artery. Then perforating branches from the paraesophageal vein to the lower part of esophagus were disconnected

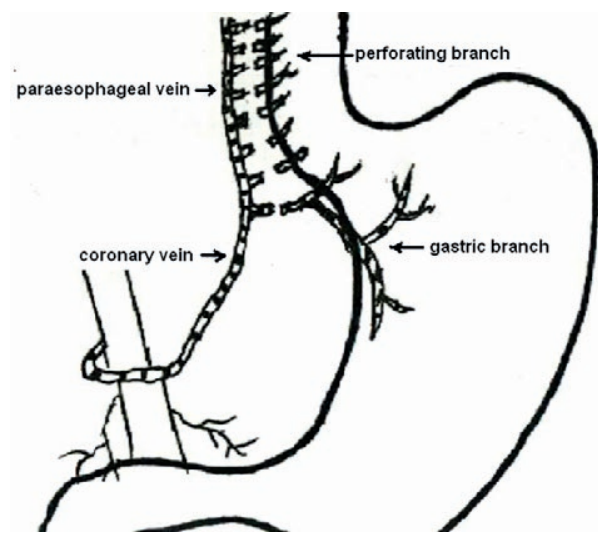

Fig 1. Perforating branches from paraesophageal vein to the lower part of esophagus were disconnected and suture ligated. Dissection was made close to the esophagus and lesser gastric curvature. Dissection of the lower part of esophagus was performed up to the esophageal hiatus level.

and the suture ligated, trying to keep the paraesophageal vein entire. Dissection of the lower part of esophagus was performed up to $7-10 \mathrm{~cm}$ above the cardia (the esophageal hiatus level) (fig 1). The whole layer discontinuous suture guided by a stomach tube with 3-0 prolene threads was performed around the lower part of esophagus at the area of 2-10 cm above the cardia. The seromuscular layers of the lesser curvature were closed with interrupted silk sutures. Finally, the FPP was remeasured. Before suturing the abdominal incision, a peritoneal cavity drainage tube was placed at the left subphrenic location. The technique of standard PDS was applied as described by Hassab et al [8].

\section{DU examination}

DU was performed with a combined ultrasonic system consisting of a scanner (ACUSON Sequoia ${ }^{\mathrm{TM}} 512$, Color Doppler equipment). The study was performed in all cases by the same examiner in order to avoid interobserver variables. The examiner was not aware of the treatment. Spectral waveforms were obtained at measured angles of insonation of $<60^{\circ}$. Firstly, a longitudinal section of the vessel was obtained, and then the sample volume of the DU system was placed in the middle of the vessel. The angle correction was made manually during examination. The smallest possible velocity scale and the lowest possible wall filter were used. The measurements were repeated three times and an average of measurements was taken for each parameter.

Vessel diameters, mean flow velocities, blood flow of portal vein trunk (PVF), hepatic artery (HAF), and superior mesenteric vein (SMVF) were calculated. Diameters of the vessel are obtained from the longitudinal section of the vessels assuming the veins as a circular structure. The maxi- 
Med Ultrason 2014; 16(4): 291-297

mum velocity (Vmax) measurements were obtained during suspended respiration and were averaged over a few seconds. Mean velocity (Vmean) calculated from Vmax multiplied by the coefficient 0.57 was obtained directly by a dedicated software supplied with the Doppler equipment, as the vein velocity profile can be assumed to be parabolic. Blood flow (Q) was calculated from Vmean multiplied by the cross-sectional area (CSA) of the vessel: $Q=V m e a n \times C S A$. The congestion index (CI) was calculated from the CSA of vessel divided by Vmean: $\mathrm{CI}=\mathrm{CSA} / \mathrm{Vmean}$. The CSA was calculated using the formula: $\mathrm{CSA}=\pi / 4 \times \mathrm{D}^{2}(\mathrm{D}$, diameter of the vessel) [9]. In addition to the above, the presence of thrombosis in the portal vein was evaluated.

All the Doppler examinations were performed after overnight fasting, in the supine position, holding breath after a shallow inspiration. The baseline Doppler measurement was performed within three to five days preoperatively. The second Doppler examination was performed at two weeks postoperatively.

\section{Statistical Analysis}

All statistical analyses were performed using SPSS15.0 software (SPSS, Chicago, IL). Results are given as mean values_standard deviation (SD). For multiple comparisons, one-way ANOVA for repeated measures was used. Then, the student's t-test for paired samples was computed. Correlations were investigated by the least squares method. Multivariate analysis to correlate survival with prognostic factors was performed using the COX proportional hazard model. The null hypothesis was rejected if $P$-values lower than 0.05 were found.

\section{Ethics Statement}

The Review Board of our hospital approved the study. All adult subjects provided informed consent on their behalf. The informed consent given was written.

\section{Results}

\section{Preoperative comparison of the two operational groups}

There were no significant difference between the SDPDPV group and the PDS group of the preoperative database including age, gender, Child-Pugh's score and biochemical tests $(p>0.05)$ (Table I). The two groups were well balanced in the distribution of prognostic factors and other characteristics.

\section{Portal vein pressure}

As shown in table II, the difference of FPP between the SDPDPV and the PDS groups were not significant before operation and after splenectomy $(p=0.475$, $\mathrm{p}=0.562$ ). However, in contrast to the PDS group, the FPP in the SDPDPV group was much lower significantly after devascularization $(\mathrm{p}=0.011)$.
Table I. Preoperative clinical characteristics of cirrhotic patients.

\begin{tabular}{|c|c|c|c|c|}
\hline & $\begin{array}{c}\text { SDPDPV } \\
(n=138)\end{array}$ & $\begin{array}{c}\text { PDS } \\
(\mathrm{n}=98)\end{array}$ & $\begin{array}{l}\text { t/ } \chi 2- \\
\text { value }\end{array}$ & $\begin{array}{c}\mathbf{p} \\
\text { value }\end{array}$ \\
\hline Age (years, mean+SD) & $48.1+6.9$ & $46.2+8.0$ & 0.511 & 0.257 \\
\hline $\begin{array}{ll}\text { Gender } & \begin{array}{l}\text { male } \\
\text { female }\end{array}\end{array}$ & $\begin{array}{c}169 \\
49\end{array}$ & $\begin{array}{c}128 \\
30\end{array}$ & 0.332 & 0.373 \\
\hline Child-Pugh's score & $6.8+1.5$ & $6.9+1.3$ & 0.171 & 0.685 \\
\hline Albumin $(\mathrm{g} / \mathrm{L})$ & $33.9+7.3$ & $33.4+6.0$ & 0.135 & 0.722 \\
\hline ALT (IU/L) & $25.7+6.9$ & $26.9+6.3$ & 0.265 & 0.581 \\
\hline AST (IU/L) & $26.9+6.3$ & $27.5+6.7$ & 0.126 & 0.741 \\
\hline Platelets (/L) & $21.1 \times 109$ & $27.6 \times 109$ & 0.384 & 0.395 \\
\hline $\mathrm{PT}(\mathrm{sec})$ & $14.6+2.5$ & $14.8+2.3$ & 0.192 & 0.648 \\
\hline $\mathrm{TB}(\mu \mathrm{mol} / \mathrm{L})$ & $25.6+3.7$ & $25.8+4.3$ & 0.132 & 0.795 \\
\hline
\end{tabular}

The results are expressed in mean or mean+SD; SDPDPV- selective double portazygous disconnection with preserving vagus; PDS- pericardial devascularization with splenectomy; ALT- alanine aminotransferase; AST- aspartate aminotransferase; PT- prothrombin time; TB- total bilirubin; n- number of patients.

Table II. Pre- and postoperative free portal pressure ( $\mathrm{cmH} 2 \mathrm{O})$ in the study groups.

\begin{tabular}{lcccc}
\hline & $\begin{array}{c}\text { SDPDPV } \\
(\mathbf{n = 1 3 8 )}\end{array}$ & $\begin{array}{c}\text { PDS } \\
(\mathbf{n = 9 8 )}\end{array}$ & t-value & $\mathbf{p}$ value \\
\hline Preoperative & $38.1+3.2$ & $39.3+3.9$ & -0.439 & 0.475 \\
After splenectomy & $27.1+3.0$ & $27.8+2.7$ & -0.387 & 0.562 \\
Postoperative & $23.5+4.3$ & $28.2+3.93$ & 3.792 & 0.011 \\
\hline
\end{tabular}

The results are expressed in mean+SD; SDPDPV-selective double portazygous disconnection with preserving vagus; PDS- pericardial devascularization with splenectomy; $n$ - number of patients.

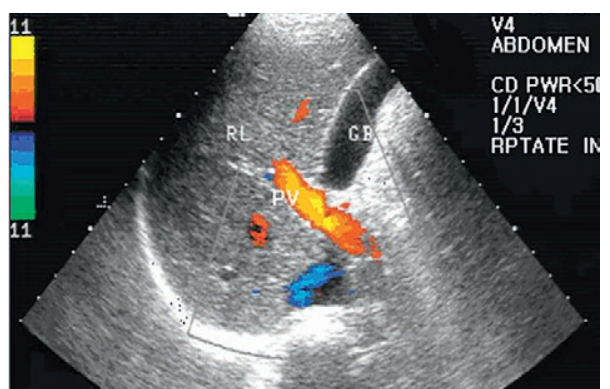

Fig 2. After SDPDPV, the diameter of PV in the patient with portal hypertension was still $1.37 \mathrm{~cm}$.

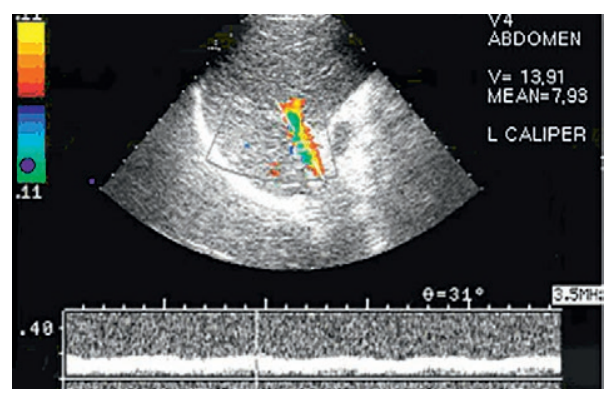

Fig 3. After SDPDPV, the velocity of PV in the patients with portal hypertension was $7.93 \mathrm{~cm} / \mathrm{s}$, much lower than that of pre-operation $(12.07 \mathrm{~cm} / \mathrm{s})$ 
Effects of selective double portazygous disconnection and devascularization

Table III. Changes in splanchnic hemodynamics before and after SDPDPV or PDS procedure.

\begin{tabular}{|c|c|c|c|c|c|c|c|}
\hline \multirow{4}{*}{$\begin{array}{l}\text { Diameter } \\
(\mathrm{cm})\end{array}$} & \multirow{3}{*}{$\begin{array}{c}\text { Vessel } \\
\text { PV }\end{array}$} & \multicolumn{2}{|c|}{ SDPDPV $(n=138)$} & \multicolumn{2}{|c|}{ PDS $(n=98)$} & \multirow{2}{*}{\multicolumn{2}{|c|}{$\begin{array}{c}\mathbf{P} \\
\text { value }\end{array}$}} \\
\hline & & \multirow{2}{*}{$\begin{array}{c}\text { Preopeative } \\
1.39 \pm 0.16\end{array}$} & \multirow{2}{*}{$\begin{array}{c}\text { Postopeative } \\
1.38 \pm 0.21\end{array}$} & \multirow{2}{*}{$\begin{array}{c}\text { Preopeative } \\
1.38 \pm 0.20\end{array}$} & \multirow{2}{*}{$\begin{array}{c}\text { Postopeative } \\
1.32 \pm 0.21\end{array}$} & & \\
\hline & & & & & & $\mathrm{a} 0.572$ & $\mathrm{~b}_{0.145}$ \\
\hline & HA & $0.30 \pm 0.21$ & $0.35 \pm 0.14$ & $0.38 \pm 0.22$ & $0.39 \pm 0.21$ & ${ }^{\mathrm{a}} 0.475$ & ${ }^{b} 0.603$ \\
\hline & SMV & $0.75 \pm 0.19$ & $0.80 \pm 0.15$ & $0.74 \pm 0.26$ & $0.79 \pm 0.18$ & $\mathrm{a} 0.192$ & $\mathrm{~b}_{0} 0.211$ \\
\hline \multirow{3}{*}{$\begin{array}{l}\text { Velocity } \\
(\mathrm{cm} / \mathrm{s})\end{array}$} & PV & $11.93 \pm 3.05$ & $9.01 \pm 3.46$ & $12.71 \pm 3.61$ & $11.22 \pm 2.97$ & $\mathrm{a} 0.023$ & $\mathrm{~b}_{0} 0.291$ \\
\hline & HA & $48.02 \pm 14.57$ & $71.85 \pm 13.62$ & $53.34 \pm 14.85$ & $58.27 \pm 9.85$ & ${ }^{\mathrm{a}} 0.009$ & $\mathrm{~b}_{0.182}$ \\
\hline & SMV & $7.13 \pm 2.52$ & $9.85 \pm 2.77$ & $7.03 \pm 2.36$ & $7.25 \pm 2.87$ & $\mathrm{a}^{\mathrm{a}} 0.012$ & $\mathrm{~b}_{0} 0.315$ \\
\hline \multirow{3}{*}{$\begin{array}{l}\text { Blood flow } \\
(\mathrm{ml} / \mathrm{min})\end{array}$} & PV & $963.45 \pm 209.13$ & $537.48 \pm 176.26$ & $1015.69 \pm 287.36$ & $921.05 \pm 175.43$ & $\mathrm{a}_{0} 0.004$ & $\mathrm{~b}_{0} 0.285$ \\
\hline & HA & $437.62 \pm 116.28$ & $671.43 \pm 99.13$ & $442.51 \pm 127.86$ & $506.35 \pm 88.41$ & $\mathrm{a} 0.008$ & $\mathrm{~b}_{0} 0.216$ \\
\hline & SMV & $551.27 \pm 187.75$ & $984.30 \pm 211.73$ & $568.95 \pm 136.32$ & $616.85 \pm 192.77$ & ${ }^{\mathrm{a}} 0.000$ & $\mathrm{~b}_{0} 0.193$ \\
\hline CI (cmxsec) & PV & $0.14 \pm 0.03$ & $0.18 \pm 0.05$ & $0.13 \pm 0.04$ & $0.14 \pm 0.04$ & ${ }^{\mathrm{a}} 0.018$ & $\mathrm{~b}_{0.392}$ \\
\hline
\end{tabular}

a - comparison of before and after SDPDPV; b - comparison of before and after PDS; PV - portal vein; HA - hepatic artery; SMV - superior mesenteric vein; SDPDPV - selective double portazygous disconnection with preserving vagus; PDS - pericardial devascularization with splenectomy; CI - congestion index

Table IV. Postoperative complications.

\begin{tabular}{lcccc}
\hline Complication & $\begin{array}{c}\text { SDPDPV } \\
(\mathbf{n}=138)\end{array}$ & $\begin{array}{c}\text { PDS } \\
(\mathbf{n}=98)\end{array}$ & $\begin{array}{c}\boldsymbol{\chi} \mathbf{2 -} \\
\text { value }\end{array}$ & $\begin{array}{c}\mathbf{p} \\
\text { value }\end{array}$ \\
\hline $\begin{array}{l}\text { Recurrent } \\
\text { hemorrhage }\end{array}$ & $3(2.2 \%)$ & $13(13.3 \%)$ & 15.473 & 0.001 \\
$\begin{array}{l}\text { Encephalopathy } \\
\text { Thrombosis }\end{array}$ & $8(5.8 \%)$ & $6(6.1 \%)$ & 0.627 & 0.208 \\
\hline
\end{tabular}

SDPDPV - selective double portazygous disconnection with preserving vagus; PDS - pericardial devascularization with splenectomy

\section{Splanchnic hemodynamics}

Results of splanchnic hemodynamics examination were listed in Table III (fig 2, fig 3).

The correlation between decreased FPP and changed PVF, HAF or SMVF after SDPDPV procedure were all highly significant $\left(\chi^{2}=4.265, \mathrm{p}=0.012 ; \chi^{2}=2.710\right.$, $\left.\mathrm{p}=0.0353 ; \chi^{2}=7.791, \mathrm{p}=0.008\right)$. But no correlation were observed between changes in FPP and changes in PVF, HAF or SMVF after PDS procedure $\left(\chi^{2}=0.793, p=0.087\right.$; $\chi^{2}=0.448, \mathrm{p}=0.273 ; \chi^{2}=0.316, \mathrm{p}=0.220$ ).

\section{Postoperative complications}

The incidence of recurrent hemorrhage, encephalopathy, and portal vein thrombosis (fig 4) are listed in table IV.

\section{Operative mortality}

The operative mortality rate was $0.7 \%(1 / 138$, one case with acute portal vein thrombosis) in the SDPDPV group and 4.1\% (4/158, 2 cases with variceal bleeding,

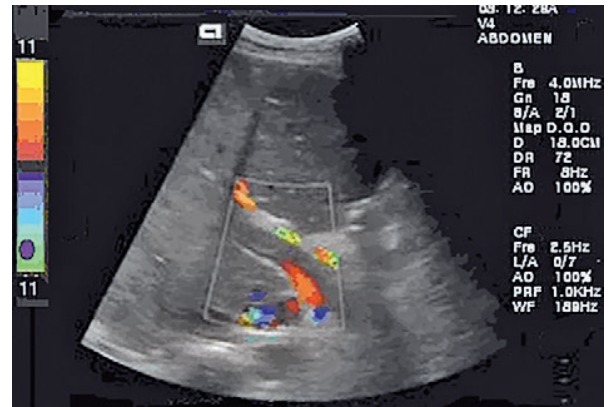

Fig 4. Doppler ultrasound showed a fillingdefect in the portal vein after SDPDPV. A few blood flow signals could be seen around it (noncomplete block).

one case with hepatic function failure, and one case with portal vein thrombosis $)$ in the PDS group $\left(\chi^{2}=5.812\right.$; $\mathrm{p}=0.009$ ).

Uni- and multivariate analysis of predictors for postoperative rebleeding and thrombosis

Postoperative rebleeding was significantly correlated with PVF $(p=0.007)$ and SMVF $(p=0.003)$. In addition, the emergence of PV thrombosis was associated with portal CI $(\mathrm{p}=0.031)$ (Table V). Multivariate Cox proportional hazard analysis revealed that preoperative PVF $(p=0.011)$ and SMVF $(p=0.028)$ were significantly independent prognostic indicators of postoperative rebleeding, whereas HAF and portal CI were not. Furthermore, the DU parameter including PVF, HAF, SMVF and portal CI were not significantly and independently associated with the emergence of PV thrombosis after the SDPDPV procedure $(\mathrm{p}>0.05)$ (Table VI). 
Table V. Univariate analysis of predictors for rebleeding and thrombosis after SDPDPV

\begin{tabular}{lcccccc}
\hline Variables & $\begin{array}{c}\text { Rebleeding } \\
\text { Posi- } \\
\text { tive }\end{array}$ & $\begin{array}{c}\text { Nega- } \\
\text { tive }\end{array}$ & $\begin{array}{c}\text { P- } \\
\text { value }\end{array}$ & $\begin{array}{c}\text { Thrombosis } \\
\text { Posi- } \\
\text { tive }\end{array}$ & $\begin{array}{c}\text { Nega- } \\
\text { tive }\end{array}$ & $\begin{array}{c}\text { P- } \\
\text { value }\end{array}$ \\
\hline PVF (ml/min) & & & & & & \\
$\quad \leq 963$ & 0 & 62 & $0.007^{*}$ & 16 & 46 & 0.261 \\
$\quad>963$ & 3 & 73 & & 10 & 66 & \\
HAF (ml/min) & & & & & & \\
$\quad \leq 437$ & 2 & 64 & 0.284 & 11 & 55 & 0.312 \\
$\quad>437$ & 1 & 71 & & 15 & 57 & \\
SMVF (ml/min) & & & & & & \\
$\quad \leq 551$ & 3 & 72 & $0.003 *$ & 17 & 58 & 0.062 \\
$\quad>551$ & 0 & 63 & & 9 & 54 & \\
PCI (cmxsec) & & & & & & \\
$\quad \leq 0.14$ & 2 & 66 & 0.173 & 4 & 64 & 0.031 \\
$>0.14$ & 1 & 69 & & 22 & 48 & \\
\hline
\end{tabular}

PVF - blood flow of portal vein trunk; HAF - blood flow of hepatic artery; SMVF - blood flow of superior mesenteric vein; PCI - portal congestion index; * is Fisher-value

Table VI. Multivariate analysis of predictors for rebleeding and thrombosis after SDPDPV

\begin{tabular}{lccccccc}
\hline $\begin{array}{l}\text { Vari- } \\
\text { ables }\end{array}$ & \multicolumn{2}{c}{ Hazard ratio } & \multicolumn{2}{c}{$\mathbf{9 5 \%}$ CI } & \multicolumn{2}{c}{ p value } \\
\hline & $\begin{array}{c}\text { re- } \\
\text { bleed- } \\
\text { ing }\end{array}$ & $\begin{array}{c}\text { throm- } \\
\text { bosis }\end{array}$ & $\begin{array}{c}\text { re- } \\
\text { bleed- } \\
\text { ing }\end{array}$ & $\begin{array}{c}\text { throm- } \\
\text { bosis }\end{array}$ & $\begin{array}{c}\text { re- } \\
\text { bleed- } \\
\text { ing }\end{array}$ & $\begin{array}{c}\text { throm- } \\
\text { bosis }\end{array}$ \\
\hline PVF & 6.46 & 1.05 & $1.32-21.78$ & $0.81-3.65$ & 0.011 & 0.173 \\
HAF & 1.83 & 0.92 & $0.75-4.66$ & $0.63-5.29$ & 0.193 & 0.286 \\
SMVF & 4.67 & 1.53 & $1.05-5.90$ & $0.92-4.81$ & 0.028 & 0.090 \\
PCI & 0.63 & 2.82 & $0.40-6.59$ & $0.98-7.64$ & 0.477 & 0.068 \\
\hline
\end{tabular}

CI - confidence interval; PVF - blood flow of portal vein trunk; HAF - blood flow of hepatic artery; SMVF - blood flow of superior mesenteric vein; PCI - portal congestion index

\section{Discussions}

DU allows the contemporaneous evaluation of a great number of splanchnic hemodynamic parameters which could be useful for pathophysiological studies as well, such as vessel diameters, mean flow velocities, or blood flow, being suitable for the non-invasive evaluation of splanchnic hemodynamic effects [10]. Moreover, the use of DU allows a new hemodynamic approach: indeed, the evaluation at the same time of the different determinants of portal blood inflow is possible [11]. The therapeutic goals of surgical procedures for PHT are mainly achieved by the selective reduction of the portal vein pressure
$[12,13]$. PDS is the main method of treatment for PHT in China. Our study illustrated that the mean value of FPP in the PDS group was lower after the operation, but FPP still remained at a high level. In contrast to the PDS group, the mean value of FPP in the SDPDPV group was significantly much lower after the operation. The main reason could be the fact that in the process of PDS, the splenectomy and the devascularization of the high-risk perigastroesophageal collateral vessels are performed. As a result all the collateral circulation may be blocked between the portal vein system and the azygos venous system, followed by a decrease in the vascular tone. As a result, the arteriolar resistance is decreased, resulting in peripheral and splanchnic vasodilatation. This is accompanied by the hyperkinetic blood flow in the splanchnic and systemic circulation. The blood flow through the splanchnic organs draining into the portal venous system may increase relatively $[14,15]$, therefore the FPP still maintain a high level. Zhan et al [16] suggested that the changes in hepatic hemodynamic status after PDS had a beneficial effect on the hepatocyte functional reserve because these provided sufficient portal vein perfusion to the liver, but these changes can promote the formation of new collateral vessels in the periesophagogastric area, and increase the risk for rebleeding. On the other hand, injuries of the paraesophageal vein and of the gastric coronary vein trunk were prevented during the procedure of SDPDPV, and then retention of these vicarious vessel channels may decrease FPP postoperatively. Similar results were obtained by Xie et al [17].

In our study there were no significant hemodynamics changes in PV, HA and SMV after PDS procedure. Moreover, there was only a slight change in PVF and CI and a significant increase of PV thrombosis appeared postoperatively. The above results indicated that there was no obvious improvement of PV stasis after PDS procedure. Previous studies have shown that the increased pressure from a gastric parietal vein would result in the stasis state of gastric mucosa after PDS, therefore the threat of gastrointestinal hemorrhage from ruptured esophageal and gastric varices or from portal hypertensive gastropathy still remained [18-20]. The removal of the spleen not only reduced the PVF, but also blocked the portoazygous collateral circulation. Furthermore, ligation of the splenic artery may improve the HAF and increase hepatic sinusoidal pressure. All of these would raise the PV resistance further. Therefore, PDS failed to completely relieve the state of PV stasis, which is the main cause of recurrent hemorrhage after operation [21,22]. Our study also showed that diameter, blood velocities and blood flow of SMV increased significantly after SDPDPV. It may be caused by a compensatory mechanism between SV and 
SMV, a mechanism regulated by the splanchnic nerve and hormone.

Comparing with PDS, the changes in hemodynamics of the portal venous system after SDPDPV were significant. The correlation between decreased FPP and decreased PVF after SDPDPV procedure was highly significant. The main reason could be that some spontaneous shunts were retained intra-operatively, thus further reducing the portal blood flow and hepatic sinusoidal pressure and increasing the hepatic artery flow velocity [23,24]. Moreover, the vasodilator mediators, including nitric oxide, were inactivated in liver due to shunts $[25,26]$. In our study, HAF and SMVF increased significantly after SDPDPV procedure, due to the decreasing of PVF to liver. SDPDPV not only reduce the FPP and prevent variceal hemorrhage but also maintain the hepatic perfusion. Our study showed a significant postoperative improvement in hepatocyte function and Child-Pugh's score in SDPDPV group comparing with PDS group.

In patients with cirrhosis, PV thrombosis secondary to splenectomy combined with devascularization has an incidence of $5 \%-25 \%$ [27]. It may be related to the hypercoagulative state including thrombocytosis and elevated blood viscosity. In addition, the blood stream in the ectatic splenic vein is very slow and may contribute to the splenic vein thrombosis [28]. Our study showed that the difference in the incidence of PV thrombosis was not significant between the two groups.

Rebleeding from ruptured varices is the main complication of portal hypertension and a major cause of death in patients with cirrhosis postoperatively. In our study, the rate of recurrent hemorrhage of SDPDPV group was very low. So, predicting the risk of postoperative rebleeding from varices seemed to be very important. Variceal grade accessed by endoscopy is correlated with rebleeding [29], but endoscopic procedure might induce variceal rupture. DU as a noninvasive method can be utilized to examine and follow up patients. We found some DU parameters including PVF and SMVF that were significantly and independently associated with rebleeding after SDPDPV. By focusing on the two indicators, we may be able to prevent rebleeding. Though portal CI was associated with the emergence of PV thrombosis after SDPDPV, it was not a significant independent prognostic indicator of PV thrombosis analyzed by multivariate analysis.

This study has several important limitations. The main clinical outcome measure of this study was in-hospital postoperative complications and 30-day mortality. This may reflect a lower complication and mortality rate because some patients might have been discharged from the hospital before the potential complications and death. Our study used population-based data with only limited information on patient and treatment factors, limiting our evaluation of medical treatments such as antibiotic use, anticoagulants (low molecular weight heparin) use, and nursing intervention. This also prevented us from being able to directly compare our results to the standard scale for measuring the severity of cirrhotic PHT.

\section{Conclusions}

Compared with the PDS, the SDPDPV apparently decreased the blood velocity and blood flow of PV, and increased the blow flow in HA and SMV which has a beneficial effect on hepatic function and encourages the control of recurrent bleeding from varices effectively. It showed that SDPDPV as a new procedure was operable, viable and safe. Moreover, PVF and SMVF may be valuable indicators to predict postoperative rebleeding.

Conflicts of interest: there was no potential conflict of interest.

\section{Reference}

1. Carbonell N, Pauwels A, Serfaty L, Fourdan O, Levy VG, Poupon R. Improved survival after variceal bleeding in patients with cirrhosis over the past two decades. Hepatology 2004; 40: 652-659.

2. McCormick PA, O'Keefe C. Improving prognosis following a first variceal hemorrhage over four decades. Gut 2001; 49: 682-685.

3. Sacerdoti D, Merkel C, Bolognesi M, Amodio E Angeli P, Gatta A. Hepatic arterial resistance in cirrhosis with and without portal vein thrombosis: relationships with portal hemodynamics. Gastroenterology 1995; 108: 1152-1158.

4. Tincani E, Cioni G, Cristani A, et al. Duplex Doppler ultrasonographic comparison of the effects of propranolol and isosorbide-5-mononitrate on portal hemodynamics. J Ultrasound Med 1993; 12: 525-529.

5. Zong GQ, Fei Y, Chen J, Liu RM. Selective double disconnection for cirrhotic portal hypertension. J Surg Res 2014 May doi:10.1016/j.jss.2014.05.065.

6. de Franchis; Baveno V Faculty. Revising consensus in portal hypertension: Report of the Baveno V consensus workshop on methodology of diagnosis and therapy in portal hypertension. J Hepatol 2010; 53: 762-768.

7. García-Pagán JC, Caca K, Bureau C, et al. Early use of TIPS in patients with cirrhosis and variceal bleeding. $\mathrm{N}$ Engl J Med 2010; 362: 2370-2379.

8. Hassab MA. Gastroesophageal decongestion and splenectomy in the treatment of esophageal varices in bilharzial cirrhosis: further studies with a report on 355 operations. Surgery 1967; 61: 169-176.

9. Moriyasu F, Nishida O, Ban N, et al. "Congestion Index" of the portal vein. AJR Am J Roentgenol 1986; 146: 735-739. 
10. Bolognesi M, Sacerdoti D, Merkel C, et al. Splenic Doppler impedance indices: influence of different portal hemodynamic conditions. Hepatology 1996; 23: 1035-1040.

11. Sabba C, Weltin GG, Cicchetti DV, et al. Observer variability in echo-Doppler measurements of portal flow in cirrhotic patients and normal volunteers. Gastroenterology 1990; 98: 1603-1611.

12. El-Serag HB, Everhart JE. Improved survival after variceal hemorrhage over an 11-year period in the Department of Veterans Affairs. Am J Gastroenterol 2000; 95: 3566-3573.

13. de Franchis R, Dell'Era A, Iannuzzi F. Diagnosis and treatment of portal hypertension. Dig Liver Dis 2004; 36: 787798.

14. Kitano S, Terblanche J, Kahn J, Bornman PC. Venous anatomy of the lower oesophagus in portal hypertension: practical implications. Br J Surg 1986; 73: 525-531.

15. Sato T, Yamazaki K, Toyota J, et al. Perforating veins in recurrent esophageal varices evaluated by endoscopic color Doppler ultrasonography with a galactose-based contrast agent. J Gastroenterol 2004; 39: 422-428.

16. Zhang Y, Wen T, Yan L, et al. The changes of hepatic hemodynamics and functional hepatic reserve after splenectomy with periesophagogastric devascularization. Hepatogastroenterology 2009; 56: 835-839.

17. Xie M, Huang J, Pan WN. The clinical significance of retain traffic branch between portal vein and azygos in selective devascularization. Zhong Hua Pu Tong Wai Ke Za Zhi 2006; 21: 689-691.

18. D’Amico G, de Franchis R; Cooperative Study Group. Upper digestive bleeding in cirrhosis. Post-therapeutic outcome and prognostic indicators. Hepatology 2003; 38: 599612.

19. Merli M, Nicolini G, Angeloni S, Gentili F, Attili AF, Riggio $\mathrm{O}$. The natural history of portal hypertensive gastropathy in patients with liver cirrhosis and mild portal hypertension. Am J Gastroenterol 2004; 99: 1959-1965.
20. Spahr L, Villeneuve JP, Dufresne MP, et al. Gastric antral vascular ectasia in cirrhotic patients: absence of relation with portal hypertension. Gut 1999; 44: 739-742.

21. Bosch J, Berzigotti A, Garcia-Pagan JC, Abraldes JG. The management of portal hypertension: rational basis, available treatments and future options. J Hepatol 2008; 48(Suppl 1): S68-S92.

22. Bureau C, Metivier S, Peron JM, et al. Prospective assessment of liver stiffness for the noninvasive prediction of portal hypertension. J Hepatol 2007; 46(Suppl 1): S34.

23. Raia S, Mies S, Macedo AL. Surgical treatment of portal hypertension in schistosomiasis. World J Surg 1984; 8: 738-752.

24. Ezzat FA, Abu-Elamgd KM, Aly IY, et al. Distal splenorenal shunt for management of variceal bleeding in patients with schistosomal hepatic fibrosis. Ann Surg 1986; 204: 566-573.

25. Huang HC, Chang CC, Wang SS, et al. The roles of angiotensin II receptors in the portosystemic collaterals of portal hypertensive and cirrhotic rats. J Vasc Res 2012; 49: 160168.

26. Nagasaka H, Miida T, Yorifuji T, et al. Metabolic improvements in intrahepatic porto-systemic venous shunt presenting various metabolic abnormalities by 4-phenylacetate. Clin Chim Acta 2013; 419: 52-56.

27. Charco R, Fuster J, Fondevila C, Ferrer J, Mans E, GarcíaValdecasas JC. Portal vein thrombosis in liver transplantation. Transplant Proc 2005; 37: 3904-3905.

28. Fujita F, Lyass S, Otsuka K, et al. Portal vein thrombosis following splenectomy: identification of risk factors. Am J Surg 2003;69: 951-956.

29. Garcia-Tsao G, Bosch J, Groszmann RJ. Portal hypertension and variceal bleeding--unresolved issues. Summary of an American Association for the study of liver disease and European Association for the study of the liver single-topic conference. Hepatology 2008; 47: 1764-1772. 